[pp. 105-123 ]

Vol. 3(1), Enero-Junio, 2015

http://dx.doi.org/10.15359/rnh.3-1.6

\title{
Envejecer sanamente
}

\section{Healthily Growing Old}

Carlos Fernando Morúa Carrillo

Universidad Nacional, Sede Central

Heredia, Costa Rica

carlos.morua.carrillo@una.cr
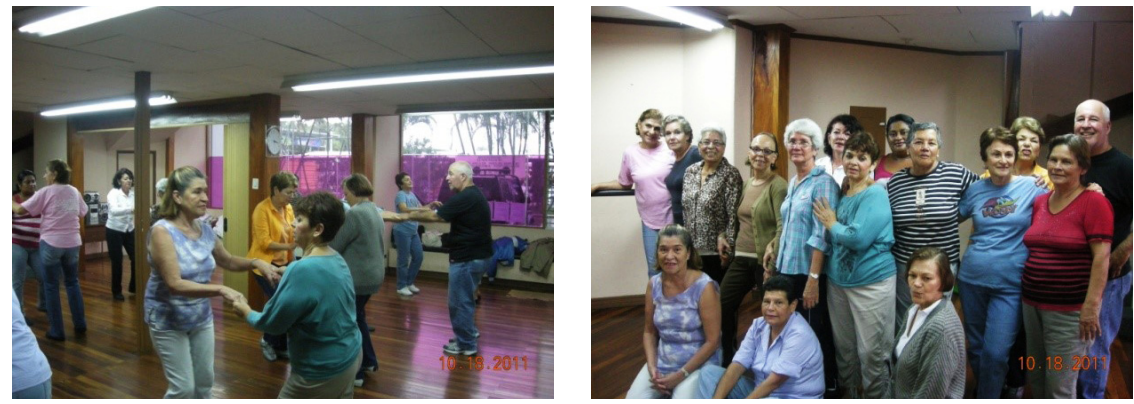

Figura 1. Taller de baile y movimiento creativo 2011. Nos comunicamos a través del cuerpo mediante el movimiento.

Fuente: Foto propiedad de Carlos Morúa.

\section{Resumen}

El artículo corresponde a una experiencia de aprendizaje sobre el encuentro y trabajo con personas adultas mayores en el taller de Danza y Movimiento Creativo. Este taller formó parte de las actividades del Programa de Atención Integral de la Persona Adulta Mayor (PAIPAM) del Centro de Estudios Generales de la Universidad Nacional (CEG-UNA). El curso se impartió por espacio de cuatro años $(2009,2010,2011$ y 2012), ad honorem, desde el mes de febrero hasta noviembre de cada ciclo lectivo. El propósito del taller fue ofrecer un espacio de encuentro a estas poblaciones participantes, para que mediante el ejercicio, el movimiento creativo y la improvisación, descubrieran

y desarrollaran una conciencia corporal, de una manera lúdica y espontánea. A su vez, se buscó contribuir en la mejora de la calidad de vida de las personas participantes. Esto fue 
posible gracias a la implementación de diversas y variadas estrategias, que fomentaron la participación, la integración, la interacción. Interesó, además, descubrir la variedad y riqueza de la experiencia de estas poblaciones, con el firme interés del desarrollo de una libre expresión creativa, desde los diversos ámbitos del saber.

Palabras clave: Adulto mayor, envejecimiento, motivación, ser humano, trabajo en equipo, improvisación, conciencia, calidad de vida.

\begin{abstract}
The article corresponds to a learning experience in meeting and working with elderly people in the Dance and Creative Movement workshop. This workshop was a part of the activities of the Integral Care Program for the Elderly (PAIPAM, for its initials in Spanish) of the Center of General Studies of Universidad Nacional (CEG-UNA). The course was offered for four years (2009, 2010, 2011 and 2012), pro bono, from February until November of every school period. The intention of the workshop was to offer these individuals an opportunity to get together so that, through exercise, creative movement and improvisation, they would discover and develop bodily awareness, in a playful and spontaneous manner. Another goal was to contribute to the improvement in the quality of life of the participants. This was possible through the implementation of different strategies, which encouraged participation, integration, and interaction. It was also a goal to discover the variety and the value of the experience for these individuals, with the firm interest of developing free creative expression, from the different scopes of knowledge.
\end{abstract}

Keywords: Elderly, aging, motivation, human being, team work, improvisation, conscience, quality of life.

\title{
Introducción
}

Durante cuatro años de trabajo (2009-2012) en el Programa de Atención Integral de la Persona Adulta Mayor (PAIPAM) en el Centro de Estudios Generales (CEG) de la Universidad Nacional, Costa Rica, se logró desarrollar esta experiencia de aprendizaje, donde se compartió con personas adultas mayores, en calidad de instructor, específicamente en el taller de Danza y Movimiento Creativo. El curso se impartió, ad-honoren, desde febrero a noviembre de cada año por el período indicado. El propósito fue ofrecer un espacio de encuentro con este tipo de población, para que mediante el ejercicio, el movimiento creativo y la improvisación, descubrieran 
y desarrollaran una conciencia corporal de manera lúdica y espontánea, lo cual a la vez estimula su calidad de vida emocional y física.

Se implementaron diversas estrategias que fomentaron la integración y la interacción entre las personas participantes. De esta experiencia, se infiere un aspecto fundamental: la importancia de crear conciencia dentro del ámbito universitario, tanto con los estudiantes como con los profesores, sobre la necesidad de abrir espacios de atención, por medio de cursos, dirigidos a las poblaciones de las personas adultas mayores. La experiencia obtenida en estos años en el CEG mostró que estas actividades de movimiento son factibles de realizar y contribuyen a fomentar el interés de estas poblaciones de adultos mayores, por acercarse de una manera espontánea y natural al campus universitario. Además, cumplen un papel fundamental en el fortalecimiento de la autoestima en esta población.

\section{El Centro de Estudios Generales de la UNA}

El Centro de Estudios Generales (CEG) posee una amplia trayectoria histórica, ya que nace con la Universidad Nacional (UNA) y forma parte de la identidad que ha caracterizado a esta casa de educación superior desde su fundación. A lo largo del tiempo, ha venido desarrollando actividades de docencia y extensión por medio de los diversos programas y proyectos, con el firme interés de fortalecer la formación humanística de sus estudiantes y con el constante propósito de brindar un soporte educativo que promueva una formación integral y participativa, donde se desarrolle una libre expresión creativa, desde los diversos ámbitos del saber.

Con este fin se crea, el Taller de Danza y Movimiento Creativo, que busca ofrecer un espacio dentro de la Universidad para la población adulta mayor, donde se espera comprender y atender de manera práctica, el Humanismo, como conocimiento y forma de vida.

\section{El adulto mayor}

Con el paso de los años, la etapa de la vejez alcanza todo el cuerpo humano, tanto en lo interno, como en lo externo. Se van produciendo cambios, transformaciones, donde se van perdiendo algunas facultades, producto del deterioro de los diferentes sistemas en el organismo. Estas transformaciones afectan los diferentes aspectos de la vida del ser humano. Aprender y conocer sobre todos esos cambios es una tarea necesaria, con el propósito de obtener una mejor calidad de vida. Diversos 
estudiosos resaltan la importancia de irse preparando con tiempo para esta etapa que le llega a todo ser humano: la vejez.

Pont (2003) expresa: "Son muchos los años que permiten prepararse para la vejez. A lo largo de toda la vida se tiene la posibilidad de disponerse a vivir una ancianidad sana y equilibrada y de aceptar la llegada de ese momento evolutivo de una manera positiva y natural" (p.22).

Desde esta visión, una persona consciente de que el tiempo incide en esas transformaciones en su cuerpo debe mostrar interés por mantener una actitud positiva, por tener hábitos saludables y fomentar la participación constante en actividades que le ayuden a mejorar las condiciones físicas y mentales, para llegar a tener una vejez más sana y tranquila. El Consejo Nacional de la Persona Adulta Mayor (CONAPAM, 2007a) escribe una definición que engloba la condición de envejecimiento:

La condición de envejecimiento de las personas se caracteriza por lo singular y la interacción con el entorno (familia, sociedad). De esta manera, va a depender del género, de la edad biológica y cronológica, del autocuidado, la historia de vida, la condición de salud y también de la situación social, económica, cultural, educativa, y socio familiar de cada persona (p.2)
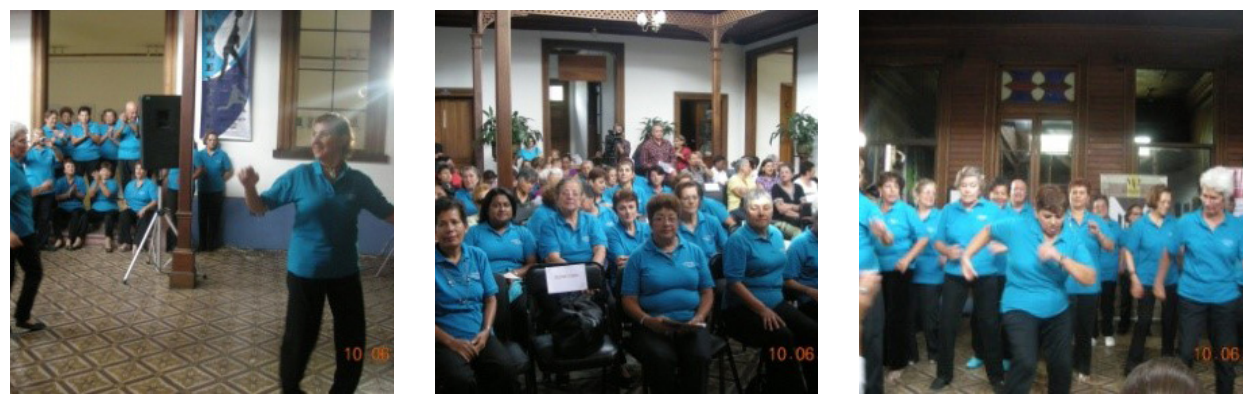

Figura 1. Celebrando el día del adulto mayor, Casa de la Cultura, Heredia, 2011 Fuente: Foto propiedad de Carlos Morúa.

Nota: El taller de baile brinda grandes beneficios a la salud por medio del ejercicio y el baile, mejora la respiración y la circulación sanguínea y fortalece los huesos.

La persona adulta mayor que participa de los talleres culturales del PAIPAM en la Universidad Nacional busca, por lo general, actividades que los distraigan y entretengan y motivaciones que le ayuden aprovechar el tiempo, aprendiendo nuevos conocimientos, estimulando y ejercitando su parte física, (motora fina y gruesa), su mente, su autoestima y la seguridad en sí mismos. Las personas 
adultas mayores muestran un interés por estar reunidos junto a otros adultos, en espacios colectivos compartiendo, dialogando. En este sentido Pont (2003), valora muy positiva la actitud y participación de estas personas mayores en diversas actividades "....si una persona mayor realiza fuera de su hogar actividades físicas y sociales que le permitan mantener joven su cuerpo y su espíritu, será una persona capaz de adaptarse a nuevas situaciones y a nuevos cambios sociales." (p.64)

El trabajo con personas adultas mayores en el taller de baile y movimiento creativo, impartido por el maestro Morúa a lo largo de cuatro años, contribuyó a trabajar aspectos que estimularon el cuerpo y la mente y las emociones, así como destrezas de motora fina, motora gruesa, captación, coordinación, interacción y trabajo en equipo. Al calor del ejercicio, del movimiento y del uso de la música, se estimuló la sensibilidad. En este sentido, concordamos con Pont (2003), cuando expresa la importancia del ejercicio físico:

Hay que considerar la importancia del ejercicio físico a una edad en que las facultades tienden a declinar y necesitan del mantenimiento de la función para conservar activos todos los sistemas que rigen el organismo: sistema nervioso, sistema muscular, sistema óseo-articular, etc. (p.56)

Programas como el PAIPAM, desde su nacimiento en 1996, plantea desde el Humanismo una visión inclusiva, que tiene que ver con la oportunidad de crear espacios que contribuyan al estímulo y sensibilidad de los sentidos, a las oportunidades de comunicación, participación y el establecimiento de redes entre las poblaciones de adultos, espacios y oportunidades donde puedan ser escuchados y observados tal como son. Esto supone la búsqueda constante de estilos de vida saludable y el fomento de una mejor calidad de vida a través de los talleres culturales y artísticos.

La educadora María de los Ángeles Chaves (2004) expresa que "en la naturaleza del arte existen varios comunicantes entre la necesidad de expresión, la sensibilidad y el pensamiento del hombre; el arte prepondera y mantiene a los individuos cercanos a la humanidad".

En los tiempos actuales se le ha dado una gran importancia al tema del cuido y la atención de las personas adultas mayores en beneficio de su salud. Se han creado libros sobre modos de entretenimiento y atención para esta población. En Costa Rica el CONAPAM es la entidad que procura marcar la pauta, en hacer conciencia sobre los individuos sobre la atención a esta población adulta mayor: 
Existen variadas actividades recreativas, de ocio y esparcimiento, educativas, de convivencia y de capacitación, en las que se puede participar para mejorar la calidad de vida con intención de mantener la autonomía y la independencia, prevenir mayores niveles de dependencia y fortalecer la autoestima a medida que las personas envejecen. (CONAPAM, 2007b, p. 7)

El taller de baile y movimiento creativo que se impartió buscó siempre la posibilidad de que estas poblaciones mayores lograran moverse, que se integraran a un grupo y fueran despertando y conociendo nuevas posibilidades de movimiento. Para ello la música jugó un papel de estímulo, al sensibilizar y crear atmósferas de trabajo, por ejemplo al bailar un merengue o una cumbia se genera una alegría y el cuerpo reacciona y se mueve, pero al sonar un danzón, paso doble o bolero el movimiento crea recuerdos de sus vidas y les provoca hablar y comentar sobre ello. No hay necesidad de interrogar a nadie, pues poco a poco van contando otras experiencias de vida. Así se crea la confianza entre ellos.

El movimiento, el juego y el deporte facilitan los contactos con otras personas, haciendo que se den rasgos en común en el juego, experiencias en grupo al hacer ejercicios conjuntamente, movimientos y juegos: se tiene ocasión de hablar con más gente, se pueden intercambiar opiniones, se supera el aislamiento y el retiro social, que a menudo van unidos a la edad. (Baur \& Egeler, 2001, p. 8)

Cualquier actividad artística o cultural en la que participen las personas mayores logrará funcionar si ellos mismos aportan su asistencia, energía e interés para el buen desempeño y para obtener logros. Al trabajar el cuerpo físico con una rutina de ejercicios, la disciplina es fundamental para crear hábitos y realizar las indicaciones y obtener logros. Conocer la población permitirá trabajar en pos de una vida plena, saludable y activa.
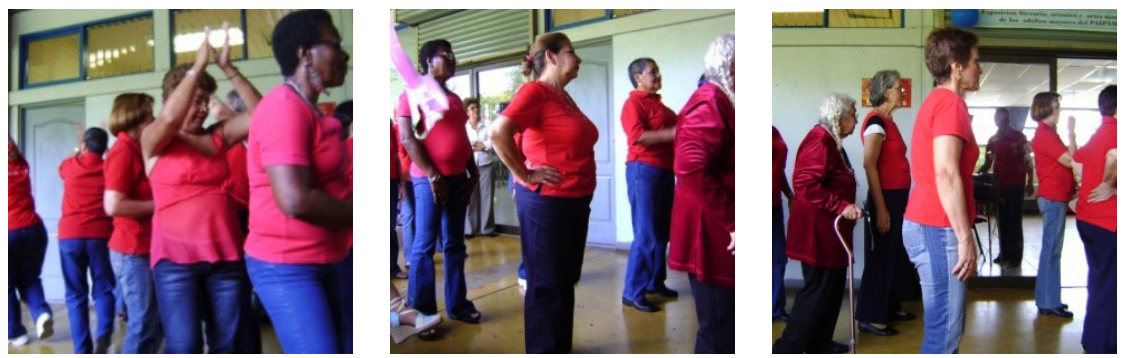

Figura 2. Celebrando el día del adulto mayor, pasillos del Centro Estudios Generales, 2009. Fuente: Foto propiedad de Carlos Morúa.

Nota: En el taller de baile se descubren nuevas posibilidades de movimiento con el cuerpo 


\section{Inicios de la experiencia}

Desde el 2009, fue posible vivenciar una nueva experiencia como docente: el trabajo con personas adultas mayores. Con el apoyo de la coordinadora del PAIPAM, MSc. Maribel León Fernández, fue posible que abrir un curso de baile y movimiento creativo para estas poblaciones. La característica de los cursos de este programa es que permiten que personas adultas mayores se acerquen a la Universidad y participen en diversos cursos libres.

\section{Objetivos de Taller de Danza y Movimiento Creativo}

- Brindar a la población adulta mayor del PAIPAM un espacio de encuentro que propicie la recreación y esparcimiento, por medio de un taller de baile, con el propósito de promover un estilo de vida saludable y que contribuya a mejorar su calidad de vida.

- Fomentar entre todas las personas adultas mayores participantes del taller, la integración, la participación y el respeto mutuo de una manera espontánea, a través del juego, la improvisación y el movimiento.

\section{El baile como recreación y esparcimiento}

El espacio se diseñó especialmente para la recreación y el esparcimiento, con el propósito de estimular la convivencia, la creatividad y la participación de los adultos mayores en las actividades, de una forma lúdica y espontánea.

Durante los cuatro años del proyecto, las lecciones del taller iniciaron en el mes de febrero y terminaron en el mes de noviembre. El tiempo de duración de cada sesión de trabajo fue de dos horas y media, con una frecuencia de una vez por semana. La tabla 1 muestra lo realizado. 


\section{Tabla 1}

Curso de baile y movimiento creativo

\begin{tabular}{|c|c|c|c|c|}
\hline Datos / Año & 2009 & 2010 & 2011 & 2012 \\
\hline Inicio & Febrero & Febrero & Febrero & Febrero \\
\hline Término & Noviembre & Noviembre & Noviembre & Noviembre \\
\hline Día & Miércoles & Miércoles & Martes & Martes \\
\hline Hora & 1:00 a 3:30 p.m. & 1:00 a 3:30 p.m. & 1:00 a 3:30 p.m. & 1:00 a 3:30 p.m. \\
\hline Lugar & $\begin{array}{l}\text { Sala de Exdeca- } \\
\text { nos CEG }\end{array}$ & $\begin{array}{l}\text { Sala de Exdeca- } \\
\text { nos CEG }\end{array}$ & $\begin{array}{l}\text { Palacio de los } \\
\text { Deportes* }\end{array}$ & $\begin{array}{l}\text { Sala de Exde- } \\
\text { canos CEG }\end{array}$ \\
\hline $\begin{array}{l}\mathrm{N}{ }^{\circ} \text { de } \\
\text { participantes }\end{array}$ & 35 & 40 & 35 & 35 \\
\hline
\end{tabular}

Fuente: Carlos Morúa instructor grupo de baile.

Nota: En el año 2011 debido a la falta de espacio dentro del Centro de Estudios Generales, el taller se trasladó a un aula del Palacio de los Deportes.

\section{Aspectos metodológicos}

La metodología aplicada buscó siempre la participación e integración de todos los participantes del taller, basadas en pequeñas secuencias de movimiento guiadas por el docente y en secuencias libres e improvisadas de movimiento espontáneo realizadas en el momento al calor de la música de merengue, danzón, cumbia, cha cha cha y otras. En algunas ocasiones se utilizaron mantas o bolas, etc. También se aprovecharon diversas técnicas o procedimientos para la realización de actividades lúdicas tanto formativas (de desarrollo personal), como participativas, (de iniciativa), incluso en espectáculos.

El taller de baile se convirtió en un espacio de encuentro propicio para que las personas adultas participantes pudieran para disfrutar al máximo el tiempo extraído de sus rutinas diarias. La buena asistencia también facilitó el trabajo y 
la integración. Fue necesario para un mejor aprovechamiento del tiempo y del esfuerzo de todos los participantes, dividirlo en cinco partes:

- En la primera, el profesor impartía un calentamiento, que tenía el propósito de ejercitar el cuerpo, así como estimular el trabajo de concentración y coordinación.

- La segunda parte, el profesor solía poner la música y motivar a las adultas mayores a bailar. El ritmo musical jugó un papel importante, porque ayudó a fomentar la inspiración para soltarse y moverse. En ocasiones él dirigía la improvisación y los demás lo seguían, en otras eran las participantes del taller los que guiaban. Rosa fue una de las participantes que siempre mantuvo una actitud muy propositiva y colaboradora con sus compañeras, guiando y proponiendo grandes ideas para realizar en el espacio, lo mismo que Virgita y Flora.

- La tercera parte era completamente libre. Allí las personas se expresaban como querían, cada quien se movía a su gusto.

- La cuarta parte se destinaba para un receso en donde las participantes organizaban un café. Este espacio se convirtió en el punto de encuentro, socialización e información. Allí solía comentarse algo de la clase o de numerosos temas.

- En la quinta parte, todos los miembros participaban de una pequeña oración-reflexión dirigida por el maestro, que siempre buscaba inspirar confianza, autoestima y gran motivación hacia la vida. Todos la realizaban con respeto y nadie se iba hasta que no concluyera esa oración, incluso sin importar la religión. Cuando algún miembro del grupo estaba enfermo, se ponía en las peticiones. 
Tabla 2

Distribución del trabajo durante cada día de lección

\begin{tabular}{|c|c|c|}
\hline Tiempo & Actividad por realizar & Propósito \\
\hline $\begin{array}{l}\text { Primeros } 45 \\
\text { minutos }\end{array}$ & $\begin{array}{l}\text { Una rutina de ejercicios como } \\
\text { calentamiento }\end{array}$ & $\begin{array}{l}\text { Estimular la circulación sanguínea y } \\
\text { la respiración, trabajo de las articula- } \\
\text { ciones y del cuerpo físico en general. }\end{array}$ \\
\hline $\begin{array}{l}\text { Siguientes } 60 \\
\text { minutos }\end{array}$ & $\begin{array}{l}\text { Actividades que involucraron } \\
\text { el uso del espacio, la coor- } \\
\text { dinación, la creatividad e } \\
\text { imaginación }\end{array}$ & $\begin{array}{l}\text { Fomentar la creación de rutinas de } \\
\text { bailes, estimulados por del uso de } \\
\text { diferentes ritmos musicales. }\end{array}$ \\
\hline $\begin{array}{l}\text { Durante } 20 \\
\text { minutos }\end{array}$ & $\begin{array}{l}\text { Dinámicas dirigidas al trabajo } \\
\text { de improvisación en equipos } \\
\text { libres de todos los participan- } \\
\text { tes, en el taller }\end{array}$ & $\begin{array}{l}\text { Generar pequeñas secuencias } \\
\text { de movimiento improvisadas y } \\
\text { dirigidas por grupos }\end{array}$ \\
\hline $\begin{array}{l}\text { Durante } 15 \\
\text { minutos }\end{array}$ & Toma de café & $\begin{array}{l}\text { Promover la socialización y el } \\
\text { diálogo entre todos los participantes. }\end{array}$ \\
\hline 10 minutos & Oración en grupo & Reflexión final \\
\hline
\end{tabular}

Fuente: Carlos Morúa instructor grupo de baile.

\section{Contenidos generales del taller}

- Desarrollo de actividades que permitieron sensibilizar y estimular las capacidades, mentales y motrices del cuerpo por medio de la música y el movimiento.

- Desarrollo de actividades que permitieron estimular las capacidades de movimiento del cuerpo por medio de la improvisación y el juego.

\section{Las participantes más constantes del taller durante estos años fueron:}

Susana Álvarez, Margarita Badilla, Olga Mora, Virgita Méndez, Nury Rivas, María del Socorro Hernández, Flora Castro, Lidia Hernández, Vilma Rodríguez, Yanira Campos, Magdalena Cordero, Alicia Cascante, Ana Isabel Núñez, María Santos, Lourdes Corea, Cristina Chaves, Carlos Varth, Enid Esquivel Salas, Mery González, Marlene González, Elsa Fernández, Liz Núñez, Rosa Vindas , María Eugenia Fernández, Virginia González. 


\section{Algunos productos del taller}

Gracias al estímulo y confianza generados con la participación en el taller fue posible realizar ejercicios prácticos de movimiento y baile para ser presentados ante un público, básicamente en actividades de celebración del día del adulto mayor en los años 2009, 2010, 2011.

a. Coreografía Mambo, bailan: Olga Mora, Virgita Méndez, Flora Castro, Yanira Campos, Ana Isabel Núñez, Enid Esquivel Salas, Mery González, Liz Núñez, Virginia González.

b. Pequeña Improvisación, elaborada e interpretada por Enid Esquivel y Virgita Méndez

c. Merengue: interpretan todas las personas participantes del taller.
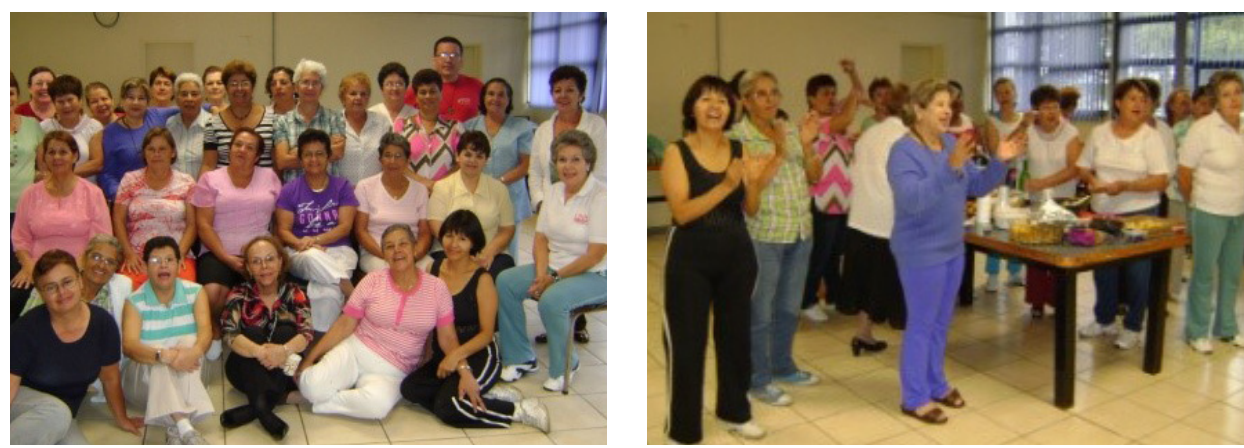

Figura 3. Celebración final del ciclo lectivo, I semestre del 2010.

Fuente: Foto propiedad de Carlos Morúa.

Nota: El taller de baile tuvo el propósito de estimular, la convivencia, la creatividad y la participación de los adultos mayores en diversas actividades, de una forma lúdica y espontánea.

\section{Logros del taller de baile con adultos mayores}

En el trabajo del taller de baile con las poblaciones de adultos mayores fue posible desencadenar procesos que estimularon el ejercicio, la sensibilidad, la creatividad, la recreación y el esparcimiento, con el propósito de procurar una mejor calidad de vida y favorecer la promoción de la salud. Con la asistencia constante de los miembros del grupo en cada semana se fue logrando poco a poco mayor participación. Esto permitió que se conocieran todas las personas integrantes del taller entre sí, que descubrieran las posibilidades y limitaciones del movimiento 
de su cuerpo. También ayudó a que se les quitara el temor, la pena o la timidez a la hora de moverse en la clase, lo que vino a generar una confianza porque fueron capaces de ayudarse unos a otros con el propósito de aprender. Así con el paso del tiempo, se fomentó la integración, donde todos se vieron como iguales, como personas que venían a recibir una clase de baile.

La constancia favoreció una especial ejercitación, motivación, mejoramiento de la salud física y emocional, la socialización, tanto en los momentos de baile, como en los recesos. Asimismo, la cohesión de grupo generó redes de apoyo incluso fuera del taller, pues se preocupaban por la salud y se trataban de cuidar entre todos.

Específicamente los aportes a la salud física generados por el ejercicio y el baile consistieron en el mejoramiento de la respiración, la circulación sanguínea, el fortalecimiento de los huesos. Igualmente se logró un adecuado estímulo al desarrollo de la imaginación y la creatividad, gracias al uso de las variadas piezas musicales, que los impulsó a moverse sin complejos.

En relación con el aporte a la salud emocional, el taller permitió que las personas participantes se sintieran motivadas, sonrieran por sus logros y disfrutaran sus movimientos. El aprendizaje de nuevos conocimientos vinculados con la coordinación motriz fortalece la capacidad del cerebro, reflejó una autoestima más saludable y agilizó los progresos con confianza y seguridad.

Desde el inicio de cada taller se logró crear una atmósfera de trabajo, alegre, divertida con respeto, orden y disciplina mediante un encuadre pedagógico acorde con las condiciones de las personas participantes. Este espacio abierto fue un gran acierto, debido a que la población atendida mostró gran interés y constantemente participó con gran disposición en las propuestas emprendidas.

Cuando estas personas llegaban a la clase, parecían olvidarse de sus problemas, al entregarse alegremente al trabajo, al baile, al conversatorio, porque siempre tenían algo que decirse o contarse entre sí; incluso durante los descansos se formaban grupos para seguir conversando. 


\section{Proceso de retroalimentación: aprendiendo de nuestras experiencias}

- Obstáculos por vencer: Uno de los grandes problemas para poner en funcionamiento el taller fue la necesidad de encontrar un espacio amplio y adecuado para impartirlo, debido a que las aulas del CEG no son aptas para que este tipo de población reciba lecciones de baile. Su tamaño no permite un trabajo adecuado: son pequeñas, tienen el techo bajo, el piso es de mosaico y no cuentan con aire acondicionado. Una solución factible fue utilizar la Sala de Exdecanos, que es un espacio más amplio y se puede adaptar a ciertas facilidades para esta población. Otro detalle importante que se consideró es que este taller tendría un carácter participativo, con la posibilidad de brindarlo a aquellas personas que no tuvieran ningún conocimiento sobre el movimiento. Se estableció que el número máximo de participantes fuera de 35 , situación que fue modificándose a través de los años, porque existía un grupo como de 20 personas estables y otro tanto que fluctuaban. Un aspecto importante cada primer día de clase fue realizar un diagnóstico rápido sobre el estado de las condiciones físicas y motoras de los participantes del taller, para verificar si presentaban algún tipo de dificultad seria o de impedimento físico que le impidiera su libre participación.

- Aportes musicales: La música en un taller de movimiento es fundamental, pues sirve de estímulo para moverse y motivarse. Es interesante como doña Flora Castro siempre se preocupó porque el profesor tuviera música variada. Por iniciativa de ella misma, gravaba discos y se los entregaba al profesor, solamente por el simple interés de que el taller contara con suficiente material en discos compactos (CD) para usar durante las clases. Algunas veces otras compañeras la imitaban o simplemente compartían su música, como lo hicieron Virgita Méndez y doña Lidieth.

- Doña Lily era una persona de cabello blanco, el cual siempre usaba amarrado con dos colitas a los lados. Tenía muchos años de usar bastón al caminar y cada vez que llegaba al curso ella se transformaba, tiraba el bastón y empezaba a bailar. Le gustaba que la felicitaran y le hicieran ruido, la pasaba muy bien en el taller. A veces traía poemas que ella componía y los 
leía en clase, de verdad disfrutaba este espacio de ser escuchada. El curso le ofreció esta posibilidad.

- Doña Susana es una señora de Alajuela que siempre participaba del curso. Le agradaba mucho y se entretenía bastante. Se caracterizaba por ser muy risueña, lo cual contagiaba a las demás participantes. Un día, entra y se mantiene sentada durante toda la clase. Se le pregunta por qué no participa y responde que le duelen mucho sus piernas. ¿Por qué no se quedó en la casa le preguntó el maestro? Ella le respondió: - ¡está loco, cómo me voy a perder este espacio, mi espacio, si me encanta!

- La mamá de Virgita, vivía en San Carlos. Cuando visitaba a su hija Virgita en Heredia y ambas aprovechaban para venir juntas al taller. Lo curioso es que esta madre, aunque se sentaba y no bailaba, disfrutaba asistir para observar lo que ocurría en el taller y ver a todas las personas moverse. Su mayor placer era gozar al ver a los demás. Asistía con frecuencia porque eso le generaba mucho entusiasmo.

- La hora del café. Por iniciativa de las participantes, se acordó compartir un café al final de cada clase. Para ello las adultas mayores se organizaron, traían el pan o galletas y el CEG colaboraba con el café (durante los primeros tres años). Para el cuarto año ellas lo traían todo, se turnaban. Siempre solía convertirse en un "mercado" pues todo el mundo empezaba hablar y contarse historias. Fui testigo cuando en muchas ocasiones salían en carrera a comprar algo porque se les había olvidado. Incluían al profesor en este espacio, con mucha atención y dedicación. El rato del café fomentó el apoyo solidario entre los participantes, porque vino a fortalecer vínculos, a crear redes de amigos y compañeros, que contribuyeron a tener una vejez digna.

- Trabajo de organización: antes de concluir cada ciclo lectivo, las personas adultas mayores se organizaban para que en la última clase cada una trajera un platillo o bebida y se compartiera. De esta forma, se lograba desarrollar una gran celebración con variedad de bocadillos y bebidas saludables. Esto solía ocurrir a mitad de año en el mes de junio. En el mes de noviembre del 2011, las personas participantes del taller asistieron a un convivo y fiesta de final de curso, en las instalaciones del Centro de Recreo del Fondo, en Barva, Heredia. Se realizaron juegos tradicionales como brincar la cuerda, juegos de mesa, lotería, entre otros. También se compartió la comida, hubo música, se bailó y todos los participantes del taller asistieron. Se disfrutó mucho hasta las cuatro de la tarde. Algo parecido ocurrió al final del ciclo lectivo 2012, pero esta vez en la finca 
de ANDE, en San Pablo de Heredia. Sin duda estos espacios fueron parte fundamental en el curso para propiciar la integración y el esparcimiento, además de fomentar la unión de los integrantes del taller.

- El tercer año nos sacaron del Centro. Para el 2011, por falta de espacio dentro del CEG, el taller de baile fue trasladado al "Palacio de los Deportes". El espacio que se les brindó fue amplio, un salón a la par de la piscina, aunque no se contaba con sillas a los lados para que esta población se sentara, ni equipo con parlantes. Dadas las circunstancias tampoco se contaría con el café (la hora de socialización), pues no había percolador ni conserje que lo sirviera. El PAIPAM contaba con una grabadora que fue la que se usó. No obstante, en ese salón a veces solían hacerse reuniones y en varias ocasiones las mismas personas adultas mayores debían ordenar antes de iniciar las clases. A mitad del curso, el taller fue trasladado a otro espacio más pequeño, incluso con columnas en medio del salón. Todo este tipo de situaciones se convirtieron en un gran inconveniente y una desmotivación; sin embargo, esta población estaba tan deseosa de recibir el taller, que pronto se adaptó a las condiciones presentes.

\section{¿Y así lo vivimos?}

\section{Proceso de reflexión: mi aprendizaje con estas poblaciones}

La experiencia resultó ser muy interesante, pero más que ello enriquecedora y valiosa, desde un enfoque humanístico: promotor de vida. Fue un gran reto trabajar con esta población, porque hay hermosas motivaciones y vivencias que surgen del compartir, aprendizajes en medio de situaciones de gozo y con sentido. Desde el ángulo de docente, hubo que reflexionar sobre las habilidades, paciencia, tolerancia, empatía y respeto por este tipo de población.

Por muy pequeñas que parezcan estas acciones, suelen generar enseñanzas significativas, de ida y vuelta, entre unos y otros. Aquí todos aprendimos, crecimos y llevamos ese aprendizaje a otros espacios donde nos relacionamos. Las participantes reflejaban esperanza, en medio quizás de situaciones que cargaban con poco optimismo, pero el sentirse valoradas, les devolvió vida y salud.

Asimismo, esta experiencia permitió conocer más a fondo la manera de actuar y de pensar de los adultos mayores. No importa cuán ocupados estemos, la vida siempre llega a ser mejor cuando extendemos la mano, no para recibir, sino para ofrecer a los demás algo de lo mucho que poseemos. Eso es hacer la diferencia, eso es ser humanísticos. 
Sin embargo, es necesario hacer conciencia de que estas poblaciones de adultos mayores requieren con carácter de urgencia espacios físicos que les permitan desarrollarse dentro de la Universidad Nacional de una forma integral, un lugar con todas las condiciones estructurales que faciliten el disfrute de las actividades de movimiento y desarrollo de diversas actividades.
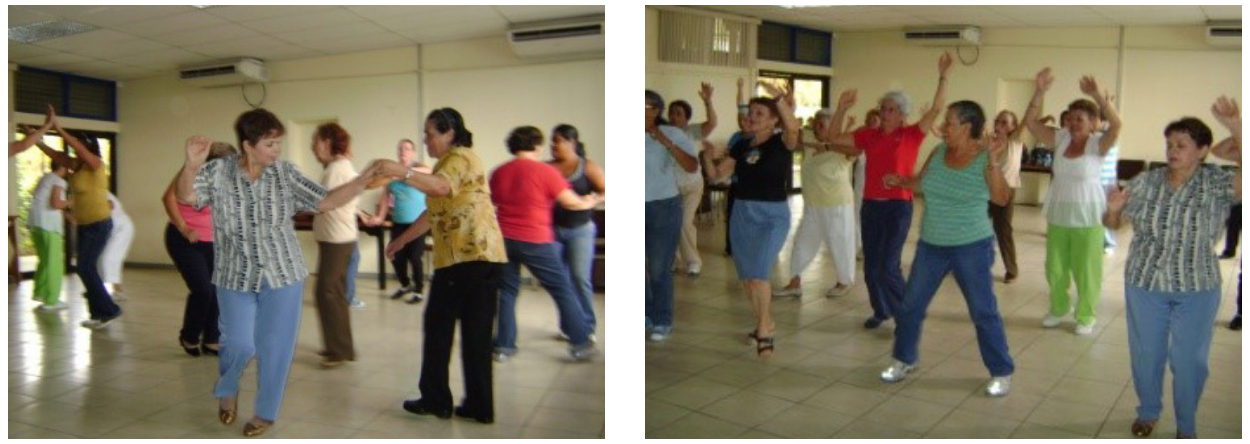

Figura 4. Grupo de baile, año 2012.

Fuente: Foto propiedad de Carlos Morúa.

Nota: En el trabajo del taller de baile con las poblaciones de adultos mayores fue posible desencadenar procesos que estimularon el ejercicio, la sensibilidad, la creatividad, la recreación y el esparcimiento, con el propósito de procurar una mejor calidad de vida y de favorecer la promoción de la salud.

\section{¿Con qué me quedo de la experiencia?}

A continuación se presenta una entrevista a la señora Virgita Méndez, que durante cuatro años formó parte del curso-taller de baile y movimiento creativo. Con 61 años destaca lo hermoso que ha sido para ella participar de esta experiencia, quien la califica como una bendición que le cambió la vida, porque le ayudó a lograr la comunicación con las personas, pues anteriormente se percibía a sí misma como tímida. Además, acentúa con vehemencia cómo en el curso ha logrado forjar grandes amistades, que ha conservado a lo largo de este tiempo. Manifiesta que este proceso le provoca alegría en su vida. Dentro de lo más significativo destacó que sin pagar un solo cinco pudo participar de una gran experiencia. Esto rompe el mito de que solo pagando se pueden alcanzar hermosas satisfacciones. 


\section{Entrevista a la señora Virgita Méndez Camacho}

Ella formó parte del curso de baile y movimiento creativo que impartió el profesor

Carlos Morúa Carrillo, en el PAIPAM durante los años 2009-2012.

Carlos: ¿Cuál es su nombre completo?

Virgita: María Virgita Méndez Camacho

Carlos: ¿Cuántos años tiene?

Virgita: Sesenta y uno

Carlos: ¿Qué le parecen los cursos de adultos mayores del PAIPAM?

Virgita: Una bendición, un espacio para hacer ejercicios y amigas. Muy importantes porque es una manera de tener mejor calidad de vida para uno, porque en la casa, uno está pensando en problemas, en cosas que le afectan la salud, en cambio en los cursos del PAIPAM se siente bien.

Carlos: ¿Cuántos años tiene de estar matriculada en los cursos?

Virgita: He estado seis años

Carlos: Y en el curso de movimiento, de Danza

Virgita: Los cuatro años con el profesor Carlos Morúa, que este año nos abandonó.

Carlos: ¿Qué le dejó ese curso?

Virgita: Para mí fue muy importante la relación con el grupo, la comunicación entre él y el adulto mayor, que uno se comunica muy poco. Muy importante porque para mí este y cada grupo lo siento como una familia. Y este grupo era muy especial, lástima que se deshizo. Para mí fue una familia muy grande, porque a veces éramos treinta o más y todos tenemos muy buenos recuerdos de todos, para mí fue súper importante.

Carlos: ¿Se mantuvo constante ese grupo?

Virgita: Siempre, bueno entraba gente nueva, pero de las que entramos al inicio nos mantuvimos casi todas.

Carlos: ¿Por qué ingresó a ese curso?, ¿quée buscaba?

Virgita: Bueno lo que yo aprendí, es que yo era muy tímida y el curso me quitó la timidez que tenía, fue muy importante para mí en ese sentido. 
Carlos: ¿De qué forma le ayudó el curso a socializar más con las personas?

Virgita: Al irlas conociendo a ellas, unas y otras, unas tenían problemas, otras no, eso me ayudó montones a comunicarme, a conversar y me empecé a soltarme y hoy por hoy soy otra persona.

Carlos: El baile de alguna manera ¿le ayudó a soltarse o ya estaba suelta?

Virgita: Bueno tal vez, siempre me ha gustado la música, pero nunca tuve la oportunidad, allí en el curso me empecé a soltar realmente, fue la oportunidad que tuve realmente de darme cuenta, que eso es lo que me gusta

Carlos: ¿Qué rescata de ese grupo, de ese período?

Virgita: Las amistades que hice que siempre las mantengo, allí fue donde empecé hacerlas

Carlos: ¿Cree usted que el PAIPAM tiene buenos instructores?

Virgita: Claro que sí, todos son buenos y lo que me gusta más es que lo están dando ad honorem, lo dan con gusto y no pensando en un salario. Sacan el tiempo para hacerlo sentirse a uno bien.

Carlos: ¿Cree que el PAIPAM debería tener unas instalaciones propias?

Virgita: Sí, porque hay veces se tienen que suspender los cursos porque no hay aulas donde impartirlos. Las oficinas del PAIPAM son muy pocas y si en la Universidad están las aulas ocupadas, uno pierde las lecciones, eso le duele a uno mucho, porque uno tiene la mente preparada de que va a ir a disfrutar. A veces llaman y le dicen a uno que no hay lecciones, entonces una se queda triste en la casa.

Carlos: ¿Usted aconsejaría a otras personas para que se matriculen en estos cursos?

Virgita: Claro que sí, para mí fue como un empezar a vivir porque yo nunca salía de la casa y yo se lo recomiendo a cualquier persona que es adquirir otro empujón de vida.

Carlos: Algo más que tenga que decir, que no le he preguntado

Virgita: Yo siempre que converso en las casas con gente adulta que no ha tenido la oportunidad, yo siempre se lo recomiendo, porque es disfrutar, tal vez lo que uno no disfrutó de joven porque estaban creciendo los niños. Y ahorita para tener más calidad de vida. Toda actividad física debe ser adaptada a las posibilidades de cada individuo. 


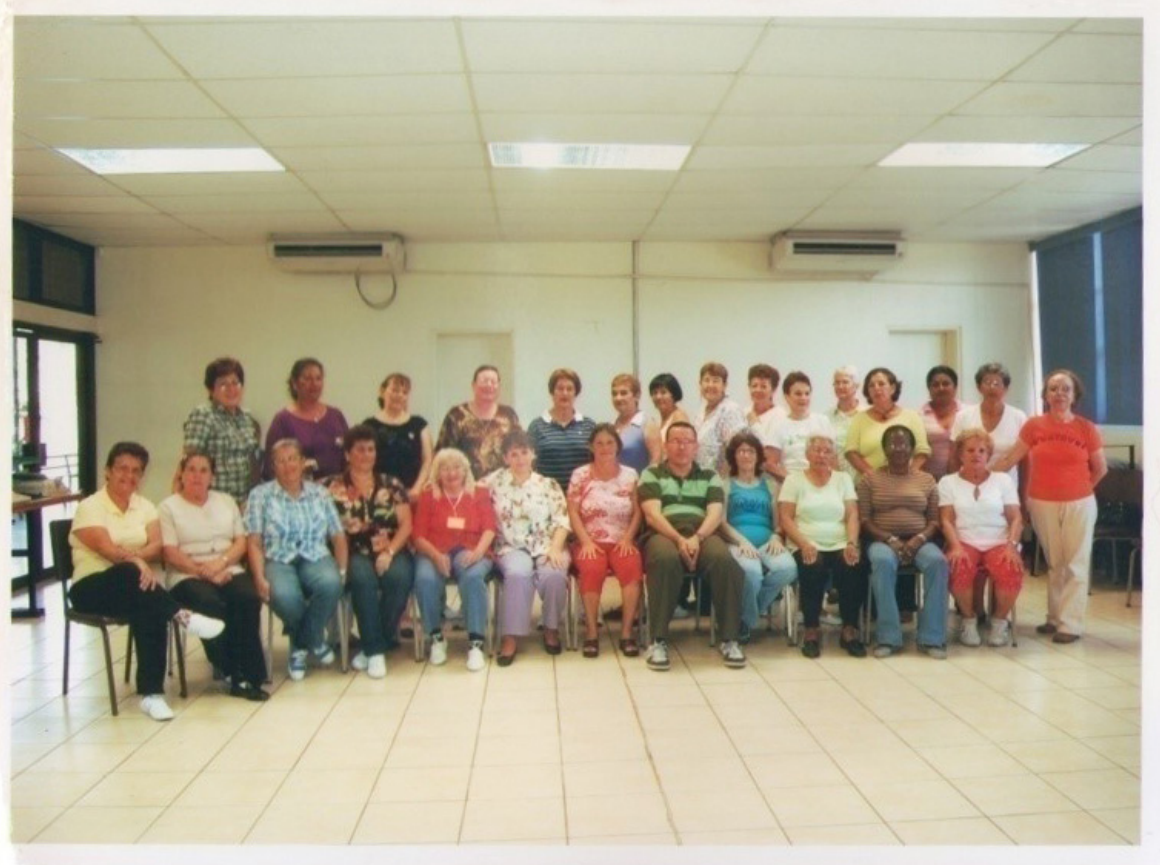

Figura 5. Grupo baile adulto mayor año 2010.

Fuente: Foto propiedad de Carlos Morúa.

\section{Referencias}

Baur, R. \& Egeler, R. (2001). Gimnasia, juego y deporte para mayores. Barcelona: Editorial Paidotribo.

Chaves, M. (2004). Educación sensorial a través del arte: educación, percepción e inteligencia a través del arte para jóvenes con Síndrome de Down. México: Editorial/ Distribuidor Conaculta.

CONAPAM (2007a). Proceso de envejecimiento. Consejo Nacional de la Persona Adulta Mayor. San José, Costa Rica

CONAPAM (2007b). Mitos y estereotipos en el envejecimiento y la vejez. Consejo Nacional de la Persona Adulta Mayor. San José, Costa Rica.

Pont, P. (2003). $3^{a}$ Edad actividad física y salud. Teoría y práctica. Barcelona: Editorial Paidotribo. 